\title{
EL NUEVO MEDIEVALISMO Y LA INTERPRETACIÓN DE LOS TEXTOS HISTÓRICOS
}

\author{
JAUME AURELL \\ Universidad de Navarra
}

RESUMEN: Desde los años setenta, la bistoriografía se ha visto sacudida por nuevas corrientes, encuadradas genéricamente bajo el poliédrico concepto de «postmodernismo». Este artículo pretende explorar el influjo de estas nuevas metodologías en el medievalismo y, más concretamente, en el de la interpretación de los textos históricos medievales. En la primera parte, se describen los postulados teóricos del llamado «nuevo medievalismo». En la segunda, se analizan los resultados de su aplicación en el análisis de la historiografía medieval, a través de algunos ejemplos entresacados de las crónicas y las genealogías francesas, castellanas y catalanas: el texto bistórico considerado como artefacto literario; la lógica social del texto histórico; la función de las genealogías; las relaciones entre el pasado, el presente y el futuro y el influjo del presentismo; la conexión entre las transformaciones literarias y las mutaciones sociales; el sentido de la prosificación y vernacularización de las crónicas y, por fin, la función política de la historiografía.

PAlabras Clave: Historiografía medieval. Postmodernismo. Nuevo Medievalismo. Crónicas. Genealogías.

ABSTRACT: Since the 1970s, historiography has been subject to new tendencies that can generally be grouped under the multifaceted concept of «postmodernism». This article explores the influx of these new trends in medievalism and, more specificly, in the intepretation of historical texts. The first part of the article describes the theoretical positions of the socalled "new medievalism». In the second part, the author analyzes the results of its application to the study of medieval historiography, using examples from French, Catalan and Castilian chronicles and genealogies. Specifically, he looks at the following key aspects of reconsidering medieval historiography in the context of postmodernism and the new medievalism: the historical text as a literary artefact; the social logic of the historical text; the function of genealogies; the relationship between past, present and future and the idea of presentism; the connection between social mutations and literary transformations; the prosification and the vernacularization of the chronicles; and the political function of historiography. 
KEY WORDS: Medieval Historiography. Postmodernism. New Medievalism. Chronicles. Genealogies.

El influjo del postmodernismo en la historiografía actual ha tenido como consecuencia un replanteamiento de los métodos y las categorías que estaban más asentados en la disciplina histórica ${ }^{1}$. Fruto de esta renovación, los historiadores actuales son más capaces de entender y valorar la historiografía medieval, sirviéndose además de la gran labor desarrollada por los historiógrafos de los dos siglos anteriores. En este nuevo contexto intelectual, los textos históricos medievales dejan de concebirse como un documento histórico poco fiable, donde de vez en cuando se intercalan pasajes legendarios espurios que hay que depurar. Las crónicas son analizadas ahora como una realidad coherente en sí misma, tanto histórica como literaria, que precisa de unas condiciones específicas para su comprensión y que, por tanto, no pueden ser analizadas basándose exclusivamente en nuestra rígida mentalidad racional ${ }^{2}$.

Partiendo de estas premisas, este artículo pretende explorar las nuevas metodologías que se han incorporado al análisis de los textos históricos medievales en los últimos treinta años. Para ello, voy a proceder desde la teoría a la práctica: en la primera parte, describo el influjo y la aplicación de las nuevas tendencias al medevalismo, analizando más detenidamente la corriente conocida como «el nuevo medievalismo», que es la concreción del postmodernismo aplicado a

${ }^{1}$ Este artículo es una versión revisada y actualizada del texto presentado para el Congreso «The State of Medieval Studies», desarrollado en la Illinois University - Urbana, del 25 al 27 de septiembre de 2003. Guardo una deuda de gratitud por los comentarios recibidos durante las sesiones de ese congreso por parte de Stephen Jaeger, Miri Rubin y Anne H. Hedeman, y los posteriores consejos de Gabrielle M. Spiegel, Paul Freedman, Ignacio Olábarri, Rocio G. Davis y Tom Shippey. Estas ideas son las reflexiones teóricas surgidas surgidas durante el proceso de elaboración de dos trabajos sobre la historiografía catalana medieval: AURELL, Jaume: "From Genealogies to Chronicles: the Power of the Form in Medieval Catalan Historiography», Viator. Medieval and Renaissance Studies, 36 (2005), pp. 235-264 y la preparación de la conferencia «Le roi autbiographique: auto-représentation et narration historique dans la Catalogne médiévale», para el seminario sobre autobiografia medieval dirigido por el Prof. Jean-Claude Schmitt en l'École des Hautes Études en Sciences Sociales de París.

${ }^{2}$ Cito algunos de los trabajos que he utilizado como referentes metodológicos para la redacción de este artículo: PATterson, Lee: Negotiating the Past: The Historical Understanding of Medieval Literature, Madison, 1987; BrownleE, Marina S., BrownleE, Kevin y Nichols, Stephen G., eds.: The New Medievalism, Baltimore, 1991; Frantzen, Allen J.: Speaking two Languages. Traditional Disciplines and Contemporary Theory in Medieval Studies, Albany, NY, 1991; WORKMAN, Leslie J., ed.: Medievalism in England, Cambridge, 1992; Engen, John Van, ed.: The Past and the Future of Medieval Studies, Notre Dame, Ind., 1994; BLOCH, R. Howard y Nichols, Stephen G., eds.: Medievalism and the Modernist Temper, Baltimore, 1996; BIDDICK, Kathleen: The Shock of Medievalism, Durham \& London, 1998; UTZ, Richard y SHIPPeY, Tom, eds.: Medievalism in the Modern World, Turnhout, 1998; Aurell, Jaume y Crosas, Francisco, eds.: Rewriting the Middle Ages in the Twentieth Century, Turnhout, 2005. 
los estudios medievales; en la segunda parte, más práctica, me focalizo en los aspectos que han emergido de la nueva lectura de los textos históricos medievales, partiendo de ejemplos entresacados de las crónicas francesas, castellanas y catalanas: el texto histórico considerado como artefacto literario; la lógica social del texto histórico; la función de las genealogías; las relaciones entre el pasado, el presente y el futuro y el influjo del presentismo; la conexión entre las transformaciones literarias y las mutaciones sociales; el sentido de la prosificación y vernacularización de las crónicas y, por fin, la función política de la historiografía.

Parto de la convicción de que, tal como han sugerido los nuevos planteamientos teóricos, es preciso un acercamiento a la historiografía medieval a través de una adecuada combinación interdisciplinar entre la historia y la crítica literaria. Por este motivo, en estas páginas no distingo entre una aproximación «histórica» o «literaria» a los textos históricos, sino más bien me referiré a ambas indistintamente, aunque obviamente no puedo desentenderme del todo de mi formación de historiador.

\section{LAS PROPUESTAS DEL NUEVO MEDIEVALISMO}

La creencia de que un acercamiento racional y objetivo al pasado nos permite recobrar el significado auténtico del pasado fue puesta severamente en duda a partir de los años setenta ${ }^{3}$. Un conjunto de epistemologías y metodologías, agrupadas en torno al concepto poliédrico del postmodernismo, postularon la necesidad de acercarse a los documentos como textos, dejando de considerarlos como simples fuentes neutras desde una perspectiva intencional o ideológica ${ }^{4}$. El termino postmodernismo fue divulgado en los años ochenta, especialmente a partir de la publicación del volumen de Jean-François Lyotard, $L a$ condition postmoderne (1979), para aglutinar en un mismo concepto el cúmulo de corrientes intelectuales que, en el campo de las ciencias sociales, pretendían romper radicalmente con la tradición ${ }^{5}$. Entre las tendencias que convergieron en este primer postmodernismo cabría destacar el postestructuralismo foucaltiano, el deconstruccionismo derrideano, la nueva hermenéutica de Paul Ricoeur y Michel de Certeau, el formalismo historicista de Hayden White y todas las derivaciones asociadas al giro lingüístico, sistematizadas por Richard Rorty. Todas estas corrientes han influido, indudablemente, en el modo de concebir,

3 Una exposición sintética de esta realidad en la segunda parte del libro de IGGERS, Georg G.: Historiography in the Twentieth Century. From Scientific Objectivity to the Postmodern Challenge, Hanover, New Hampshire, 1997 y en la magnifica síntesis de BREISACH, Ernst: On the Future of History. The Postmodernist Challenge and its Aftermath, Chicago, 2003.

4 SPIEgel, Gabrielle M.: «Introduction», The Past as Text. Theory and Practice of Medieval Historiography, Baltimore \& Londres, 1997, pp. IX-XXII.

5 LYOTARD, Jean-François: La condition postmoderne. Rapport sur le savoir, París, 1979. 
de interpretar y de escribir la historia ${ }^{6}$. A partir de entonces, la experiencia ha demostrado que cualquier intento de definición o delimitación de las fronteras del postmodernismo está condenado al fracaso. El único modo de definirlo es, probablemente, analizando sus efectos en los diferentes ámbitos de las ciencias sociales, tal como algunos ya han hecho para el campo del medievalismo ${ }^{7}$.

La renovación temática y epistemológica de la disciplina histórica a partir de los años setenta ha tenido una repercusión muy notable en el campo del medievalismo. No en vano, éste ha sido uno de los ámbitos de la historia que, junto con el altomodernismo, ha liderado la renovación epistemológica de la disciplina a lo largo del siglo veinte. Medievalistas como Johan Huizinga, Marc Bloch, Georges Duby o Jacques Le Goff, han contribuido decisivamente a renovar el utillaje metodológico con el que los historiadores construyen sus textos, provengan del campo que provengan. Ciertamente, hoy día parece que la arista cortante de la innovación se ha trasladado hacia el altomodernismo, como los experimentos de Carlo Ginzburg, Natalie Z. Davis o Simon Schama parecen demostrar ${ }^{8}$. Pero no es menos cierto que, a partir de los años ochenta, el medievalismo, sobre todo norteamericano, se ha convertido en un campo de experimentación en el que los científicos sociales han buscado renovar su metodología.

En el mismo seno del medievalismo han ido extendiéndose los efectos del postmodernismo. Quizás el mejor diagnóstico de esta realidad sea el que realizaron los medievalistas norteamericanos Paul Freedman y Gabrielle M. Spiegel en un artículo programático, publicado en 1998 por encargo de la American Historical Review ${ }^{9}$. Allí describían la emergencia de un «nuevo» medievalismo que estaba incorporando los nuevos postulados, en contraste con un «viejo» medievalismo, más prudente y apegado a la tradición. Pocos años después, Stephen G. Nichols afirmaba que no es que el viejo y el nuevo medievalismo se opongan o se haya producido una ruptura radical, si no que más bien el nuevo medievalismo ha aportado un análisis de la edad media desde nuevas perspectivas y ha descubierto nuevos paisajes y temas ${ }^{10}$.

La idea de la práctica de la historia está siendo transformada progresivamente: según las nuevas tendencias, el historiador no es capaz de reconstruir el pasado sino simplemente de volverlo a hacer presente (re-presentarlo $)^{11}$. De este

6 Ver algunas de estas manifestaciones en BARRY, Peter: Beginning Theory. An Introduction to Literary and Cultural Theory, Manchester, 1995.

7 PAden, William D.: «Scholars at a Perilous Ford», en W.D. Paden, ed.: The Future of the Middle Ages: Medieval Literature in the 1990s, Gainesville, 1994, pp. 3-31.

8 GINZBURG, Carlo: Il formaggio e i vermi. Il cosmo di un mugnaio del '500, Turín, 1976; Davis, Natalie Z.: Le retour de Martin Guerre, París, 1982 y Schama, Simon: Rembrandt's Eyes, Londres, 1999.

9 FreEdman, Paul y SPIEgel, Gabrielle M.: «Medievalisms Old and New: The Rediscovery of Alterity in North American Medieval Studies», en American Historical Review, 103 (1998), p. 677-704.

10 NichOls, Stephen G., «Writing the New Middle Ages», en PMLA, 120.2 (2005), pp. 422-441.

11 Chartier, Rogier: «Le monde comme représentation», en Annales, Économies, Sociétés, Civilisations, 44 (1989), pp. 1505-1520. 
modo, aumenta la sensación de que el acceso al pasado no es directo, porque se produce a través de la mediación de los textos y de los iconos. Como consecuencia, lo que el medievalista recupera no es estrictamente el pasado, sino las imágenes de sí mismo que el pasado produce, las improntas del pasado ${ }^{12}$. Se postula así un tratamiento poliédrico de las crónicas medievales, de las que interesa tanto lo real como lo imaginario, lo verídico como lo ficcional, lo expresado como lo silenciado, por lo que la opacidad y la inestabilidad del conocimiento histórico aumentan considerablemente. Ello genera una serie de recelos bien comprensible entre los medievalistas, que ven agredida su legitimidad científica, al conmoverse sus mismos fundamentos y debilitarse la eficacia de las técnicas paleográficas, diplomáticas, epigráficas, iconológicas y codicológicas, cuyo dominio aseguraba el acceso a las realidades del pasado. El nuevo medievalismo se convierte en una ciencia no de los hechos sino de los discursos o, todo lo más, de la codificación de los hechos ${ }^{13}$.

Para las nuevas tendencias, el texto contiene significaciones múltiples, que conviene tratar desde una perspectiva poliédrica y, por tanto, pluridisciplinar. Las distancias disciplinares entre historiadores, críticos literarios, filólogos, filósofos e historiadores del arte se reducen. Se publican volúmenes colectivos en los que participan indistintamente especialistas de esos diferentes ámbitos disciplinares $^{14}$. Se accede a los textos y a las imágenes medievales tanto en su dimensión histórica como literaria y hermeneútica ${ }^{15}$. La lectura del texto medieval desde una perspectiva postmoderna se hace más viable, porque se experimenta una mayor identificación entre el texto medieval y el postmoderno. El texto premoderno (medieval) y el texto post-moderno reducen sus distancias metodológicas y epistemológicas. Ambos contrastan radicalmente con el texto histórico moderno (siglos XVI-XX), cuya univocidad está basada en una lectura empírica, científica, positivista y paradigmática de la realidad que nos llega a través de los documentos. Esa univocidad es negada tanto por los textos medievales como por los postmodernos ${ }^{16}$.

Hoy día, sin embargo, el medievalismo parece tener algunas reservas respecto a la viabilidad de las nuevas corrientes. Por poner un ejemplo bien signi-

12 Sobre el concepto de «improntas históricas» ver el magnífico ensayo de Dosse, François: Història. Entre la ciència i el relat. Valencia, 2001, pp. 154-158.

13 VANCE, Eugène: «Semiotics and Power: Relics, Icons and the Voyage de Charlemagne à Jérusalem et à Constantinople», en BrownleE, Marina S., BrownleE, Kevin y NiCHOLs, Stephen G., eds.: The New Medievalism, Baltimore, 1991, p. 227.

14 Ver, por ejemplo, UTZ, Richard y SHIPPEY, Tom, eds.: Medievalism in the Modern World, Turnhout, 1998.

15 Como se pone de manifiesto en el modélico estudio de Anne H. Hedeman sobre las ilustraciones de las crónicas francesas: Hedeman, Anne D.: The Royal Image. Illustrations of the Grandes Chroniques de France, 1274-1422, Berkeley, Calif., 1991.

16 Ideas expuestas por Greetham, David: «Romancing the Text, Medievalizing the Book», en UTZ, Richard y SHIPPEY, Tom, eds.: Medievalism in the Modern World, Turnhout, 1998, p. 409. Ver también McGann, Jerome J.: A Critique of Modern Textual Criticism, Chicago, 1983. 
ficativo, el debate sobre el postmodernismo y sus repercusiones historiográficas ha tenido una incidencia muy minoritaria en los ambientes académicos españoles ${ }^{17}$. Muchos académicos españoles muestran recelo hacia la invasión de las ideas postmodernas en el ámbito del medievalismo (procedentes además de tradiciones historiográficas lejanas), porque cuando son llevadas a sus últimas consecuencias generan un relativismo nada aconsejable para la labor científica. No en vano Lawrence Stone consideró a las tendencias postmodernas como una verdadera amenaza para la misma subsistencia de las ciencias sociales ${ }^{18}$. En efecto, el sentido común de todo académico queda conmocionado ante las afirmaciones radicales de algunos de los principales exponentes del postmodernismo, como la que profirió Hayden V. White en uno de sus artículos de los años setenta: «Ha habido una resistencia a considerar las narraciones históricas como lo que manifiestamente son: ficciones verbales cuyos contenidos son tan inventados como descubiertos, y cuyas formas tienen más en común con sus formas análogas en la literatura que con sus formas análogas en las ciencias» ${ }^{19}$.

Nadie puede negar la necesidad de una crítica serena y ponderada a los aspectos más deleznables del postmodernismo. Sin embargo, más allá de una postura acríticamente parapeteada a la defensiva, me parece importante señalar algunas de las consecuencias más saludables de estas nuevas tendencias, que por lo menos han ejercido la función de aviso sobre la comunidad historiográfica internacional: pienso que sería un error descartarlas sistemática y apriorísticamente, sin realizar siquiera el esfuerzo por conocerlas a fondo. Estos efectos benéficos son los que explican que algunos medievalistas de prestigio, sobre todo provenientes del ámbito norteamericano, hayan decidido adoptar alguno de los nuevos postulados en su quehacer científico. Quizás el más importante de esos efectos haya sido el aumento considerable del diálogo interdisciplinar que ha experimentado el medievalismo en estos últimos veinte años. La variedad y la riqueza de enfoques de los diversos volúmenes conjuntos publicados durante los años noventa (The New Medievalism, The Past and the Future of Medieval Studies, Medievalism and the Modernist Temper, Medievalism in the Modern World) son buenos exponentes de la capacidad de las nuevas corrientes para configurar espacios metodológicos comunes entre las diferentes ciencias humanas y sociales.

17 Una de las excepciones es el número monográfico que dedicó al postmodernismo la revista Historia Social (número 50, año 2003), aunque no deja de ser también significativo que la mayor parte de los artículos incluidos fueran traducciones de artículos publicados anteriormente en revistas internacionales, más que aportaciones originales de historiadores españoles.

18 STONE, Lawrence: «History and post-modernism», en Past and Present, 131 (1991).

19 «There has been a reluctance to consider historical narratives as what they most manifestly are: verbal fictions, the contents of which are as much invented as found and the forms of which have more in common with their counterparts in literature than they have with those in the sciences» (White, Hayden V.: "The Historical text as literary artifact», en Tropics of discourse. Essays in Cultural Criticism, Baltimore \& Londres, 1978, p. 82). 
Dentro de las nuevas corrientes, por otra parte, cohabitan diferentes posturas. Buena parte de los nuevos académicos, como el nada sospechoso de frivolidad Lee Patterson, se dan cuenta de que su trabajo debe estar basado en un tratamiento adecuado, sistemático y riguroso de la documentación, sin una ruptura radical con la tradición ${ }^{20}$. Otros, como Howard Bloch y Stephen Nichols, se muestran menos cautelosos, al afirmar explícitamente que no comparten la filosofía de los fundadores de la disciplina, aunque admiran y respetan su legado. De este modo, pretenden purificar y revitalizar el medievalismo, cortando con la tradición y reforzando el interior y el exterior de las fronteras de la disciplina ${ }^{21}$. Por fin, prestigiosos académicos como Leslie Workman, han llegado a postular una sutil distinción entre los estudios medievales, cuyo objetivo es el estudio científico de la edad media, y el medievalismo, que representa la aplicación de las ideas de la época medieval a las respectivas situaciones contemporáneas $^{22}$. Se puede hablar, por tanto, de unos estudios medievales unívocos y, en cambio de un medievalismo romántico, victoriano, positivista, marxista o postmoderno, lo que justifica a su vez que en la actualidad se hable de un nuevo medievalismo en contraposición del viejo medievalismo ${ }^{23}$.

El viejo medievalismo postula los valores de la tradición heredada del método científico positivista y del historicismo clásico; el nuevo medievalismo apuesta decididamente por un acercamiento presentista a la realidad medieval a través de la aplicación de los métodos situados en la órbita postmodernista. Kathleen Biddick ha afirmado que la disciplina se halla actualmente en un estado de shock, al verificarse este enfrentamiento entre el viejo y el nuevo medievalis$\mathrm{mo}^{24}$. Me parece más oportuno postular un nuevo medievalismo que aporta unas novedades metodológicas, pero que no rompe radicalmente con la tradición anterior, tal como ha sugerido recientemente Stephen Nichols ${ }^{25}$. De hecho, la historiografía no ha avanzado nunca a través de drásticas rupturas o revoluciones metodológicas, sino de nuevas corrientes que se han impuesto con el tiempo porque han sabido compaginar lo mejor de la tradición con la revitalización de las nuevas propuestas.

20 Patterson, Lee: «The Return of Philology», en Engen, John Van, ed.: The Past and the Future of Medieval Studies, Notre Dame, Ind., 1994, p. 241.

21 «We are not he (l'Abbé Migne), nor do we and the volume's contributors share the philosophy of the founders of the discipline, as much as we admire and respect their legacy" (BlOCH, R. Howard y Nichols, Stephen G., eds.: Medievalism and the Modernist Temper, Baltimore, 1996, de la Introducción de los editores, p. 21).

22 Workman, Leslie: «Editorial», en Studies in Medievalism, III.1 (1987), p. 1. Workman ha revisado posteriormente sus postulados, y ha ido evolucionando hacia una visión más integradora de los conceptos de «estudios medievales» $\mathrm{y}$ «medievalismo», influido en buena medida por los planteamientos más continuistas expuestos en su polémico libro por Norman F. Cantor, Inventing the Middle Ages. The Lives, Works, and Ideas of the Great Medievalists of the Twentieth Century, Nueva York, 1991.

23 UTZ, Richard y SHIPPEY, Tom: «Medievalism in the Modern World: Introductory Perspectives», UTZ, Richard y SHIPPEY, Tom, eds.: Medievalism in the Modern World, Turnhout, 1998, p. 5.

24 BIDDICK, Kathleen: The Shock of Medievalism, Durham \& London, 1998, p. 2.

25 Nichols, Stephen G., "Writing the New Middle Ages», en PMLA, 120.2 (2005), pp. 422-441. 
Sea como fuere, todas estas nuevas corrientes han llevado a los medievalistas a reconsiderar algunas de las realidades que parecían más asentadas en la disciplina. Algunos de ellos han denunciado que la disciplina académica del medievalismo había quedado aprisionada por la asunción de una serie de técnicas - la diplomática, la paleografía o la edición de textos- que asegurarían un procedimiento adecuado desde el punto de vista formal, pero no garantizarían el acceso a la realidad del pasado. Por este motivo, sin olvidar en absoluto la necesidad de esas técnicas, han postulado al mismo tiempo que el medievalista tiene que tener presente que los documentos que utiliza contienen una ideología, una intencionalidad, reflejan en sí mismos una lectura del mundo y por tanto requieren una interpretación crítica que les ponga en conexión con su contexto ${ }^{26}$.

Todas estas ideas han ido cuajando en el campo del medievalismo a través de una corriente conocida con el genérico apelativo de New Medievalism. En su programático artículo de 1998, Paul Freedman y Gabrielle M. Spiegel se referían al surgimiento de un nuevo medievalismo, cuyos temas de interés se centrarían en los aspectos más identitarios de la edad media (sin necesidad de considerarlos simplemente como precedentes de los valores modernos del estado, el renacimiento o la ciencia racional), frente a un viejo medievalismo, que seguía avanzando prudentemente en sus investigaciones, sin despegarse excesivamente de las fuentes y de los temas más tradicionales. Sin embargo, paradójicamente, el alto precio que había tenido que pagar el nuevo medievalismo en su búsqueda de lo específicamente medieval era una patente radicalización de sus temas, que se escoraban hacia los ámbitos más marginales, como la marginalidad, pobreza, la brujería o las manifestaciones macabras de la vida y de la muerte ${ }^{27}$. Probablemente, Freedman y Spiegel tomaron algunos de sus conceptos del volumen conjunto que, unos años antes, en 1991, había publicado un grupo de investigadores norteamericanos (historiadores y críticos literarios), al que habían puesto precisamente el significativo título de The New Medievalism ${ }^{28}$.

¿Qué hay de verdaderamente «renovador» en esta tendencia? Partiendo de un mínimo conocimiento de la evolución de la historiografía durante los siglos XIX y XX, hablar de nuevo medievalismo a principios del siglo XXI puede parecer excesivamente pretencioso ${ }^{29}$. La razón es bien sencilla: a lo largo del siglo veinte, la disciplina histórica ha sufrido continuos cambios de paradigmas. La experimentación de estas frecuentes mutaciones metodológicas y epistemológicas ha tenido como consecuencia una sensación de renovación continua en

26 SpIegel, Gabrielle M.: The Past as Text. Theory and Practice of Medieval Historiography, Baltimore \& Londres, 1997, pp. 5-10.

27 Freedman, Paul y SPIEgel, Gabrielle M.: «Medievalisms Old and New: The Rediscovery of Alterity in North American Medieval Studies», en American Historical Review, 103 (1998).

28 Brownlee, Marina S., Brownlee, Kevin y Nichols, Stephen G., eds.: The New Medievalism, Baltimore, 1991.

29 Sobre el sentido de «lo nuevo» en la historiografía, ver Aurell, Jaume: La escritura de la memoria, de los positivismos a los postmodernismos, Valencia, 2005, pp. 159-164. 
la disciplina histórica. El apelativo «nueva» ha sido de este modo asociado a múltiples corrientes historiográficas aparecidas a lo largo del siglo. Esto ha llevado a algunos historiadores a cuestionarse el sentido de «lo nuevo» en la disciplina histórica porque, en realidad, en muchas ocasiones es difícil objetivar las aportaciones reales de esas pretendidas novedades, que en no pocas ocasiones degeneran en simples modas efímeras ${ }^{30}$.

De hecho, a lo largo de la historia, siempre ha habido intelectuales que han aspirado a reemplazar la vieja historia por una nueva, que fuera más objetiva y menos narrativa, más científica y menos literaria. ${ }^{31}$ En el siglo XIX, Ranke aspiró a la creación de una historia verdaderamente científica y objetiva; ese fue el contexto que llevó al historiador alemán Robert Fruin a publicar un ensayo titulado «La nueva historiografía» para defender la historia científica postulada por Ranke ${ }^{32}$. El historiador norteamericano James Harvey Robinson utilizó la expresión new history para referirse a la nueva forma de hacer historia que estaban desarrollando las nuevas generaciones de principios del siglo XX: Karl Lamprecht en Alemania, Henri Pirenne en Bélgica, Henri Berr en Francia y Frederick J. Turner en Norteamérica ${ }^{33}$. Para muchos otros historiadores, en cambio, la nueva historia está asociada al movimiento de la nouvelle histoire francesa, identificada a su vez con la radical transformación que postuló la escuela de los Annales desde su fundación en $1929^{34}$. La fórmula fue explicitada unas décadas más tarde por el medievalista Jacques Le Goff, quien la utilizó como título para una colección de ensayos que trataban sobre nuevos problemas, nuevas aproximaciones y nuevas objetivos de la historia. ${ }^{35}$ La nouvelle histoire se basaba en la aspiración a una historia total: «Toute forme d'histoire novelle est une tentative d'histoire totale» ${ }^{36}$. Esa tendencia se declaraba nueva en contraposición con el paradigma tradicional historiográfico asociado al viejo historicismo alemán decimonónico, que a su vez se había postulado como «nueva historia» en su momento.

Además, en el mismo siglo veinte se produce todavía una segunda oleada de tendencias verdaderamente renovadoras a partir de los años setenta y ochenta. Este es el sentido de la expresión nuevas nuevas historias, con la que se

30 Burke, Peter: «Overture: the New History, its Past and its Future», P. Burke, ed.: New Perspectives on Historical Writing, Cambridge, 1991, pp. 1-23.

31 ORR, Linda: «The Revenge of Literature», en New Literary History, 18 (1986), pp. 1-22.

32 Reeditado en FrUIN, Robert: «De nieuwe historiographie», en Verspreide Geschriften, 9 (1904), pp. 410-418.

33 BOIA, Lucian: «Introduction», BOIA, Lucian, ed.: Great Historians of the Modern Age, Nueva York, 1991, p. XII.

34 CAMpbell, Peter R.: «The New History: the Annales School of History and Modern Historiography», LAMONT, William, ed.: Historical Controversies and Historians, Londres, 1998, pp. 189-199.

35 LE Goff, Jacques, ed., La nouvelle histoire, París, 1978.

36 La cita es de Jacques Le Goff y la recoge ARIÈs, Philippe: «La sensibilité au changement dans la problématique de l'historiographie contemporaine», GADOFFRE, Gilbert, ed.: Certitudes et incertitudes de l'histoire. Trois colloques sur l'histoire de l'Institut collégial européen, París, 1987, p. 169. 
ha querido enfatizar que las nuevas corrientes no eran más que una inflación del término «nuevo» ${ }^{37}$. Los movimientos de la nueva nueva historia estarían relacionados precisamente con el final de la crisis de la historia y con el impacto del relativismo cultural e historiográfico que representa el postmodernismo. Quizás lo más característico de estas nuevas tendencias y lo que les hace reaccionar frente a la nouvelle histoire, es que postulan una recuperación del relato y la narración en la historia ${ }^{38}$. Al mismo tiempo, reactivan unos temas que eran precisamente los que la nouvelle histoire había desechado por espurios y utilizan unos documentos que hasta ahora habían sido considerado residuales o complementarios: el trasfondo histórico de las narraciones de ficción, la historicidad de las imágenes y de los símbolos, los vestigios arqueológicos o los documentos inquisitoriales. Como alternativa a los determinismos de los paradigmas historiográficos de la posguerra, las nuevas nuevas historias proponen un acercamiento poliédrico a la realidad, basado en un concepto más amplio de cultura. En los años ochenta, el historiador norteamericano Michael Kammen sugirió la adopción de una noción de cultura en su concepción más antropológica, lo que serviría de base para la reintegración de las diferentes aproximaciones de la historia ${ }^{39}$. Durante los años ochenta y noventa, la historia social y la cultural se han disuelto en un solo campo, informando así todos los demás ámbitos de la realidad.

Todos estos movimientos de renovación han tenido un influjo real en el medievalismo y, más concretamente, en el análisis de la historiografía medieval. Desde esta perspectiva, se puede considerar el nuevo medievalismo como una renovación dentro de la renovación: sus aportaciones, basadas más en los fundamentos teóricos que en las aplicaciones prácticas, contribuyen a generar un renovado debate en el seno del medievalismo. Su función es más alertativa que propiamente metodológica. El postmodernismo y el giro lingüístico no representan propiamente un «método» cerrado, sino más bien un toque de atención sobre las dificultades epistémicas de la labor del medievalista y sobre la raíz lingüística de su quehacer tradicional.

\section{LA INTERPRETACIÓN DE LOS TEXTOS HISTÓRICOS AL TERCER NIVEL}

Todo este contexto epistemológico ha influido de manera diversa en los diferentes ámbitos del medievalismo, pero especialmente al campo de la historiografía medieval. Los textos históricos medievales han dejado de considerarse simplemente como unos documentos asépticos que pueden dar luces para el

37 El concepto nueva nueva historia lo expuso OlábARRI, Ignacio: «New New History: A Longue Durée Structure», en History and Theory, 34 (1995), pp. 1-29.

38 STONE, Lawrence: "The Revival of Narrative: Reflections on a New Old History», en Lawrence STONE: The Past and the Present, Boston, 1981, p. 74-96.

39 Kammen, Michael: "Extending the Reach of American Cultural History», en American Studies, 29 (1984), pp. 19-42. 
conocimiento de una época determinada y han pasado a ser considerados unos artefactos literarios cuya intencionalidad hay que desentrañar si se quiere alcanzar su verdadera naturaleza. De este modo, se puede localizar en estos textos históricos los diferentes niveles de las improntas que el pasado había dejado en ellos: no sólo dan pistas del período al que se refieren sino, quizás más propiamente, del período desde el que han sido articulados.

El postmodernismo ha retado a los historiadores a analizar a los textos históricos desde una nueva perspectiva, llevándoles a dudar de los «hechos objetivos» supuestamente transmitidos por ellos $^{40}$. No en vano, los textos históricos son tratados ahora desde una doble perspectiva, histórica y literaria. Las dos disciplinas, historia y literatura, están ahora más estrechamente ligadas a la hora de analizar esos textos. Las crónicas medievales son construcciones literarias, sociales y políticas que deben ser estudiadas en todas estas dimensiones. Los historiadores deben ser igualmente conscientes de su naturaleza discursiva, de sus modos literarios y de sus condicionamientos ideológicos. Los críticos literarios, por su parte, deben ser muy cuidadosos a la hora de profundizar en el contexto y las circunstancias sociales desde el que estos textos históricos fueron articulados.

El nuevo medievalismo se ha aproximado a la historiografía medieval proponiendo un estudio al «tercer nivel», complementando (no sustituyendo) la labor de edición y fijación de los textos (primer nivel) y la labor de contextualización de los textos históricos (segundo nivel). Este tercer nivel de interpretación se basa en la aplicación de las nuevas corrientes epistemológicas importadas a la disciplina desde los años setenta, provenientes de la antropología, la lingüística y la sociología. El texto histórico adquiere una entidad en sí mismo, al ser analizada la historiografía medieval desde una perspectiva mucho más amplia: como artefacto literario, como narración histórica y como intermediario entre el presente desde el que es articulado y el pasado al que hacer referencia.

Las nuevas tendencias sugieren una lectura del texto histórico no sólo como intermediario de la realidad, sino también como constituyente de la realidad en sí misma. Es bien conocido el enorme influjo de la historiografía medieval en la constitución de los valores políticos e intelectuales de las sociedades medievales. Las derivaciones más radicales del postmodernismo, como el deconstruccionismo derridano, han profundizado en la entidad retórica de los textos históricos, que los configurarían de tal modo que ahogarían cualquier posibilidad de transmisión de la realidad objetiva del pasado. Lo interesante para ellos no sería el contenido de esos textos, sino su forma y su articulación retórica.

No se pueden negar las consecuencias relativizantes que ha llevado consigo la aplicación de estas corrientes más extremas. Sin embargo — y quizás paradó-

40 Respecto al moderno debate referente a los medios lingüísticos utilizados para la transmisión del conocimiento histórico, me parecen particularmente expresivas las colaboraciones contenidas en LACAPRA, Dominick y Kaplan, STEVen L., eds.: Modern European Intellectual History: Reappraisals and New Perspectives, Ithaca, NY, 1982. 
jicamente - algunas de ellas han contribuido a enriquecer y renovar la interpretación de los textos históricos medievales, sobre todo en el ámbito del medievalismo británico y norteamericano. En efecto, estas nuevas tendencias han permitido a los medievalistas a fijar la atención en nuevos aspectos de las crónicas, que hasta ese momento habían sido considerados residuales o periféricos: los silencios de esas narraciones; las repeticiones como resultado de una intencionalidad reactivada; las motivaciones de quienes las escribieron y, sobre todo, de quienes las promovieron e inspiraron; las ficcionalidades como manifestaciones de la mentalidad de un período determinado; la forma de la narración histórica como una manifestación más de su contenido (el contenido de su forma); la dimensión política de las crónicas; la función de las genealogías; la dimensión social del lenguaje y, finalmente, la relación entre el texto y el contexto - que era una de las aspiraciones del «segundo nivel», aunque sólo como objetivo secundario.

\section{EL TEXTO HISTÓRICO COMO ARTEFACTO LITERARIO: EL CONTENIDO DE LA FORMA}

En este nuevo contexto epistemológico, los historiógrafos deben tener una formación multidisciplinar. Ellos no deberían contentarse con un estudio estrictamente filológico (al «primer nivel») e histórico (al «segundo nivel»), sino que deben aspirar a una lectura integrada de las crónicas, que conjugue historia, lingüística, antropología y sociología. Así se explica que los nuevos historiógrafos provengan indistintamente de los ámbitos de la historia y de la crítica literaria, como en el caso de Gabrielle M. Spiegel y Peter Damian-Grint. A pesar de realizar un acercamiento a los textos históricos medievales desde dos disciplinas diferentes, llegan a unas conclusiones análogas en sus estudios sobre los textos históricos franceses de los siglos XII y XIII porque los leen conjuntamente en sus aspectos materiales y formales ${ }^{41}$.

Ya no se trata tanto de distinguir lo verdadero de lo falso en los textos históricos medievales, de localizar los pasajes espurios de las crónicas, como de analizar las relaciones entre el texto y el contexto. Se parte de la idea de que esas narraciones tienen una intencionalidad concreta. Se tiene en cuenta que la literatura de ficción prolifera en las sociedades sin excesivas necesidades de justificación y, en cambio, los textos históricos abundan en las sociedades problematizadas, que precisamente buscan consolidarse a través de la aprehensión de un pasado remoto glorioso. Se huye de una lectura ingenuamente racionalista y positivista de las crónicas, buscando una interpretación que tenga en cuenta sus simbologías, sus mitos, sus medias verdades y sus elocuentes silencios. Se atribu-

41 Ver especialmente SPIEgel, Gabrielle M.: Romancing de Past. The Rise of Vernacular Prose Historiography in Thirteenth Century France, Berkeley, 1993 y DAMIAN-Grint, Peter: The New Historians of the Twelfth-Century Renaissance, Woodbridge, 1999. 
ye a las crónicas medievales una «lógica social del texto», según la expresión acuñada por Gabrielle M. Spiegel: los textos históricos son al mismo tiempo producto de una sociedad y agentes de esa misma sociedad - tienen una función pasiva y otra activa ${ }^{42}$. De este modo, se abarca la dimensión histórica de los textos —el contexto desde el que fueron articulados - y su dimensión literaria, basada en el logos que debe ser analizado formalmente. Spiegel basa parte de su argumentación en las ideas desarrolladas por Mikhail Bakhtin, para el que la forma y el contenido se identifican en el discurso y, por tanto, el discurso verbal siempre tiene una dimensión social (contenido - significado) que el historiador debe percibir, sin obviar su dimensión lingüística (continente - significante. ${ }^{43}$

El contenido histórico y la forma literaria son dos caras de una misma moneda en el texto histórico medieval, y no pueden ser analizados por separado. De este modo, se abole definitivamente la artificial distinción entre unos filólogos exclusivamente preocupados por los aspectos formales del texto y unos historiadores polarizados en sus dimensiones propiamente contextuales. La forma y el contenido se identifican en el discurso histórico, porque no es posible separar el texto histórico del texto literario. Algunos postmodernos han llevado incluso a radicalizar esta postura, dotando incluso a la forma de un contenido, como lo demuestra la trayectoria del historiador norteamericano Hayden White en estos últimos treinta años. Él fue quie acuñó en 1989 la expresión The content of the form - eligiéndola como título de uno de sus volúmenes recopilatorios - en la que abogaba inequívocamente por la supremacía de los aspectos formales sobre el contenido ${ }^{44}$.

Actualmente, algunos medievalistas están tratando de buscar una vía intermedia entre los efectos más relativizantes de las nuevas corrientes y el positivismo, insuficiente hoy día para analizar con fruto las crónicas medievales. Estos nuevos historiógrafos parten de que cualquier representación del pasado está condicionada por el contexto social y su relación con las redes sociales y políticas desde las que ha sido articulada (lo que otros han denominado "presentismo»). No se trata ni de una pieza literaria de ficción aislada ni de una elucubración histórica sin soporte real. Esto le confiere al texto histórico, sea del período que sea, una evidente dimensión contextual. Los textos históricos se articulan según el contexto donde nacen. Por tanto, es preciso contextualizar

42 «In the dual sense of their relation of their site of articulation - the social space they occupy, both as products of a particular social world and as agents at work in that world- and to their discursive character as articulated logos, that is, as literary artifacts composed of language and thus requiring literary (formal) analysis»: SPIEGEL, Gabrielle M.: Romancing de Past, p. 9. Este concepto está más ampliamente desarrollado en su «History, Historicism and the Social Logic of the Text in the Middle Ages», en Speculum 65 (1990), pp. 59-86.

43 BAKHTIN, Mikhail M.: "Discourse in the Novel», en BAKHTIN, M.M.: The Dialogic Imagination. Four Essays, Austin, 1981, p. 259.

44 WhiTE, Hayden V.: The Content of the Form: Narrative Discourse and Historical Representation, Baltimore, 1989 
siempre el pasado. El historiógrafo contemporáneo sigue así el proceso inverso al historiógrafo medieval, cuyo objetivo principal era descontextualizar el pasado para acercarlo e incluso fundirlo con su presente. El historiador medieval descontextualiza el texto histórico mientras que el historiador contemporáneo trata de contextualizarlo, si bien no está nada claro cuál de los dos actúa con menos condicionantes a su alrededor. Esto explica en buena medida la tendencia de las crónicas medievales a incorporar el pasado legendario en sus pasajes históricos. Una de las claves de la enorme eficacia legitimadora de la historiografía medieval es que consigue atenuar las distancias entre un pasado remoto glorioso y un presente que hay que consolidar. Se recurre al pasado para hacer revivir sueños perdidos de gloria.

La vieja idea de Jacques Derrida de que la tradición occidental está basada en el logocentrismo (la arraigada creencia de que las palabras representan cosas) es lo que explicaría en buena medida la eficacia de la historiografía medieval. La fuerza de las narraciones históricas de los cronistas medievales proviene en buena medida de su simplicidad a la hora de representar la realidad histórica con sencillez y eficacia. En la actualidad, nuestra acusada tendencia a la crítica de los textos históricos (que es indudablemente necesaria, pero no debaría ahogar otras perspectivas) condena a las crónicas a una escasa credibilidad y capacidad normativa. Por el contrario, la eficacia de los textos históricos medievales no reside en la racionalidad de su contenido sino en la coherencia de su relato, que tan bien se aviene con las motivaciones de quienes las promocionaron y con las inquietudes de sus lectores.

\section{LA LÓGICA SOCIAL DEL TEXTO HISTÓRICO}

El análisis de los textos históricos debe tener presente la continua relación que se establece entre el texto y el contexto. Esta idea tiene, no obstante, poco de postmoderno o de neomedievalista, porque la historia social de la historiografía es algo que han tratado de hacer siempre los buenos historiógrafos. Sin embargo, es cierto que la mayor coordinación entre historia y crítica literaria ha tenido algunos resultados positivos en este ámbito concreto: se ha puesto el énfasis en que la transformación de las prácticas y las formas literarias de la historiografía remiten automáticamente a una mutación de las condiciones sociales y políticas del contexto desde las que han sido articuladas. Las variaciones formales del texto histórico representan mucho más que unas simples mutaciones gramaticales o idiomáticas. En la Francia de principios del siglo XIII ya no son suficientes las crónicas rimadas o la literatura épica de las canciones de gesta. Es preciso modernizar el discurso histórico y ponerlo a la altura de las nuevas técnicas y de las nuevas demandas de las élites y de la sociedad. Los audaces objetivos de la monarquía de los Capetos precisan de unos instrumentos adecuados para llevarlos a cabo. Entre ellos, destaca la utilización de la narración 
histórica como legitimación de las aspiraciones territoriales basadas en las conquistas militares. En la Francia de comienzos del siglo XIII, Felipe Augusto trata de legitimar su agresiva política expansiva intentando recuperar el pasado glorioso del Imperio carolingio. En la Cataluña del siglo XIII, las sobrias genealogías que contenían las Gesta Comitum Barcinonensium divulgada en el siglo XII, son sustituidas por la narración epopéyica de las conquistas de los nuevos monarcas, como se muestra en la Cronica de Jaume I o Llibre dels fets: la revitalización de la expansión peninsular y mediterránea de los monarcas de Aragón precisa de unos textos históricos legitimadores que van mucho más allá de los que habían construido sus antecesores, los condes de Barcelona ${ }^{45}$.

A partir del conocimiento del contexto desde el que los textos fueron articulados, el historiador es capaz de adentrarse en la intencionalidad, la ideología, la manipulación, las motivaciones y los objetivos de los textos históricos. Las formas literarias adoptadas por los textos históricos (annales, calendarios, cronologías, genealogías, cronicones, crónicas) son un reflejo de todos los condicionantes del contexto desde el que han sido generados. El texto histórico no es nunca un objeto aislado, inherente en sí mismo, sino que es esencialmente relacional. Su significado pleno emerge sólo en el momento en que se conoce bien el ambiente y el contexto en el que fue elaborado.

La recíproca relación entre el texto y el contexto, entre el lenguaje y la sociedad, fue enunciada sutilmente por Caroll Smith-Rosenberg: «mientras que las diferencias lingüísticas estructuran la socidad, las diferencias sociales estructuran el lenguaje» ${ }^{46}$. Según el momento epistemológico de la disciplina, se dará más importancia al texto como estructurador de la sociedad o a la sociedad como estructurante del lenguaje. En historiografía actual, sensiblemente impregnada del linguistic turn desde los años setenta, parece dominar el primer aspecto. El punto central para los nuevos historiógrafos no consiste en analizar las motivaciones del narrador ni los efectos que la narración produce sobre el lector, sino en descubrir el código a través del cual se otorga significado al narrador y al lector a lo largo del relato mismo ${ }^{47}$. Parece, pues, que lo importante no es tanto el mensaje como el procedimiento utilizado para transmitirlo. Aprovechando la máxima de que «el medio es el mensaje», los historiadores se han dado cuenta de la trascendencia de los códigos lingüísticos ${ }^{48}$. En este contexto, hay que reconocer que la tentación del formalismo en la historiografía

45 Ediciones de estos dos textos: Gesta Comitum Barchinonensium, BARRAU-DiHigo, Lucien y MAssó TORRENTS, Josep, eds., Barcelona, 1925; Llibre dels fets del rei en Jaume, BRUGUERA, Jordi, ed., 2 vols., Barcelona, 1991.

46 «While linguistic differences structure society, social differences structure language» (Smith-Rosenberg, Caroll: «The Body Politic», en Weed, Elizabeth, ed.: Coming to Terms. Feminism, Theory, Politics, New York, 1989, p. 101).

47 BARTHES, Ronald: Empire of Signs, New York, 1982. Ver también MARTín GaITE, Carmen: Cuadernos de todo, Barcelona, 2002, pp. 265-268.

48 MCLuhan, Marshall: Understanding Media, Nueva York, 1964, cap. 1. 
postmoderna está merodeando continuamente, y hay que estar vigilantes para no caer en ella. Por tanto, no es suficiente con diagnosticar las mutaciones de las formas gramaticales y los géneros literarios utilizados por las crónicas, sino que es preciso ahondar en su relación con el contexto histórico en los que esos cambios están relacionados.

Desde esta perspectiva, los textos históricos son producto del mundo social de sus autores y, simultáneamente, agentes textuales de este mundo. Deben ser estudiados, por tanto, en esta doble dimensión, como espejos de la sociedad $\mathrm{y}$, simultáneamente, como generadores de las realidades sociales. Esta es la función pasiva y activa de la historiografía, lo que Jacques Derrida llamó, quizás complicando demasiado el sentido común, la función deconstructiva y la función constructiva de los textos ${ }^{49}$. El elaborador de los textos históricos actúa simultáneamente como lector del mundo que le rodea y como escritor de ese mundo. Por tanto, los textos históricos se deben considerar tanto en su función pasiva, como reflejo de una realidad, como en su función activa, como generativa de una realidad: los textos son, simultaneamente, espejos y generadores de una realidad social al tiempo que son constituidos y constituyen formaciones sociales y discursivas ${ }^{50}$. En el texto histórico se teje el discurso que refleja una realidad social pero que al mismo tiempo construye esa realidad. Es significativo que el mismo origen etimológico de la palabra texto («tejer», del latín) delata buena parte de la carga generativa del discurso escrito. El lenguaje es fruto de la consolidación de las realidades del pasado; pero, al mismo tiempo, representa diversidades sociales del presente.

Las narraciones históricas tienen, en definitiva, una doble dimensión histórica y literaria. Deben ser consideradas tanto desde su perspectiva de artefactos históricos como literarios. Por este motivo, sus interpretaciones no pueden estar exclusivamente basadas en la interacción del texto con el contexto - tarea del historiador - como tampoco en un exclusivo análisis de los aspectos formales del texto -tarea del filólogo. En el campo de la historiografía medieval, los historiadores no deberíamos recelar de la tendencia formalista de los filólogos, porque una rigurosa recepción de las fuentes es el primer paso para su correcta interpretación. Las ediciones de las crónicas medievales, realizadas habitualmente por académicos provenientes de la filología, son indispensables para fijar el texto, pero no son suficientes para ahondar en su contenido, su significado y sus motivaciones. Al mismo tiempo, un profundo conocimiento del contexto histórico tampoco es suficiente si no va acompañado de un riguroso estudio del texto desde el punto de vista formal.

49 DERRIDA, Jacques: L'écriture et la différence, París, 1967.

50 «Texts both mirror and generate social realities, are constituted by and constitute social and discursive formations, which they may sustain, resist, contest, or seek to transform depending on the individual case». Las cursivas, que son de la propia autora, son tremendamente significativas y reflejan la doble dimensión, activa y pasiva, del texto histórico: SPIEGEL, Gabrielle M.: Romancing de Past. The Rise of Vernacular Prose Historiography in Thirteenth Century France, Berkeley, 1993, p. 10. 
LA FUNCIÓN DE LAS GENEALOGÍAS: MITIFICANDO EL PASADO PARA CONSOLIDAR EL PRESENTE

Otro de los grandes temas que interesan más a los nuevos historiógrafos es la relación que se establece naturalmente, en el seno de los textos históricos, entre el presente y el pasado. No se trata de una simple relación cronológica dialéctica, que encorseta excesivamente el texto en su contexto. La historiografía codifica una realidad pasada para fusionarla con el presente. Las crónicas medievales utilizan toda la potencia del poder mitificador del pasado. Una de las motivaciones más comunes de la historiografía medieval es la de reducir el espacio entre un pasado legendario y un presente frágil, seco, sobrio, incapaz de generar mitos ni de inventar tradiciones. Este procedimiento permite a los capetos conectar sus orígenes legendarios con la monarquía troyana a través de las Grandes Chroniques ${ }^{51}$ o a los reyes castellanos a enlazar con la monarquía visigótica, lo que legitima su agresiva política expansiva por la Península Ibérica. ${ }^{52}$ Cuanto más se aleja el cronista temporalmente, más capaz se ve de manipular los hechos, porque cuenta no sólo con el desconocimiento que se presupone en un pasado remoto sino también con su notable capacidad mitificante.

Esto explica la potencialidad y la eficacia de las genealogías históricas. Este nuevo género histórico se divulga en Europa durante la segunda mitad del siglo XII como un instrumento privilegiado para consolidar el poder monárquico, basado en la transmisión dinástica y hereditaria. La creación de una tradición histórica requiere la demostración de una continuidad social y política. Así se recoge, por ejemplo, en la introducción de las Grandes Chroniques francesas, donde se justifica la construcción de esta gran obra histórica por las dudas suscitadas por algunos sobre la veracidad de la genealogía de los reyes de Francia, de sus orígenes y de la procedencia de su linaje ${ }^{53}$. Los condes de Barcelona encargan también su genealogía, cuando devienen reyes de Aragón, para codificar su nexo genealógico con los orígenes de la dinastía. Se conecta así con el fundador de la dinastía, Guifré el Pilós, mitificando su figura, magnificando su influjo político y social y legitimando su conexión con los reyes franceses, en contraposición de visigóticos e islámicos ${ }^{54}$. La enorme eficacia de estos textos queda reflejada en las Gesta Comitum Barcinonensium, la construcción genealógica de los reyes aragoneses medievales, que se utilizó como referente histórico fundamental (un verdadero «canon») para el estudio de la edad media en Cataluña hasta bien entrado el siglo XIX ${ }^{55}$.

51 Les Grandes Crhoniques de France, ed. J. VIARD, Société de l'Histoire de France, 10 vols., París, 1920-1953, vol. I, 90 y vol. VI, 139.

52 Barbero, Abilio y Vigil, Marcelo: La formación del feudalismo en la Península Ibérica, Barcelona, 1978.

53 Cita recogida y traducida en SPIEGEL, Gabrielle M.: «Introduction», en The Past as Text. Theory and Practice of Medieval Historiography, Baltimore \& Londres, 1997, p. 96.

54 Aurell, Martin: Les noces du Comte. Mariage et pouvoir en Catalogne (785-1213), París, 1995.

55 AURell, Jaume: «La formación del imaginario histórico del nacionalismo catalán, de la Renaixença al Noucentisme (1830-1930)», en Historia Contemporánea, 16 (2001), pp. 257-288. 
La construcción de las genealogías es uno de los métodos más eficaces de unir pasado y presente, o al menos de contribuir a reducir al máximo sus distancias. Son una evidencia de la continuidad histórica, transmitida de generación en generación. Si las genealogías no existen o se han perdido, es preciso crearlas de nuevo. De ahí surgen, en muchas ocasiones, los personajes legendarios fundadores de las dinastías, como el caso de Don Pelayo para Castilla o de Guifré para Cataluña. Las genealogías representan, por otra parte, un nuevo modo de concebir el tiempo, que pasa a ser dominado por la dimensión dinástica, sustituyendo a los viejos Annales o a los Calendarios ${ }^{56}$. Al mismo tiempo, las genealogías de los siglos XII y XIII constituyen probablemente la primera secularización del tiempo en un contexto cortesano, porque las crónicas ya no necesitan remontarse a los tiempos bíblicos sino simplemente al fundador de la dinastía. La segunda y definitiva secularización del tiempo se produciría en los siglos XIV y XV, en un contexto ya urbano, al estallar la dicotomía entre un «tiempo mercantil» y un «tiempo eclesiástico», siguiendo la distinción hecha célebre por Jacques Le Goff ${ }^{5}$. A través de las genealogías el tiempo se humaniza, lo que le hace más historiable.

\section{DE LAS GENEALOGÍAS A LAS CRÓNICAS: TRANSFORMACIONES LITERARIAS Y MUTACIONES SOCIALES}

Sin embargo, a mediados del siglo XIII las genealogías parecen haber perdido vigor. Habían sido muy eficaces para legitimar la existencia de las nacientes dinastías, pero parecían insuficientes para fundamentar ideológicamente las políticas expansivas que todas ellas estaban llevando a cabo en ese momento. La recuperación de la doctrina conocida como reditus regni ad stirpem Karoli Magni y su inclusión en el ciclo de las Grandes Chroniques francesas es bien ilustrativa al respecto. Todo ello se produce, sintomáticamente, durante el expansivo reinado de Felipe Augusto, a principios del siglo XIII ${ }^{58}$. Pocos decenios más tarde, Jaime I el Conquistador construye su gran epopeya, una crónica que narra paso a paso, de modo grandilocuente, las heroicas campañas militares de la expansión catalano-aragonesa frente a los musulmanes, sin detenerse excesivamente a considerar su genealogía y sin necesidad de remitirse al pasado remoto del fundador de la dinastía ${ }^{59}$.

56 Ranum, Orest: Artisans of Glory. Writers and Historical Thought in Seventeenth Century France, Chaper Hill, N.C., 1980, p. 5.

57 Le Goff, Jacques: «Au Moyen Âge: Temps de l'Église et temps du marchand», en Pour un autre Moyen Âge. Temps, travail et culture en Occident, París, 1977, pp. 46-65 e Id., «Le temps du travail dans la crise du XIVe siècle: du temps médiéval au temps moderne», en Le Moyen Age, LXIX (1963), pp. 597-613.

58 SPIEGEL, Gabrielle M.: «The Reditus Regni ad Stirpem Karoli Magni: A New Look», French Historical Studies, 7 (1971), pp. 145-174.

59 Jaume I, Bernat Desclot, Ramon Muntaner, Pere III. Les Quatre Grans Cròniques, SoLDEVILA, Ferran, ed., Barcelona, 1971. 
Lo que muestran todas estas mutaciones de la historiografía durante el siglo XIII es que las transformaciones literarias en los textos históricos están estrechamente relacionadas con los cambios sociales y políticos ${ }^{60}$. La textualización del pasado tiene una mayor eficacia en el momento en que las monarquías europeas están llevando a cabo una política expansiva agresiva. Es el caso de los Plantagenet en Inglaterra, los Capetos en Francia, los reyes de Aragón y la monarquía castellana. En este contexto, la vernacularización y la prosificación del texto histórico forma parte de la estrategia llevada a cabo por estas dinastías, encaminada a divulgar la historia y las gestas del pasado para consolidar y justificar las acciones emprendidas en el presente. La redacción de las monumentales Grandes Chroniques de Francia y la construcción del ciclo de las Quatre Grans Cròniques de Cataluña son dos de las manifestaciones más sintomáticas de esta nueva orientación política de la historiografía medieval. El poder del texto histórico es tan grande en este momento que algunos monarcas llegan a firmar personalmente sus crónicas, como en el caso de Jaime I el Conquistador de Aragón. Aunque todavía no se ha podido demostrar hasta qué punto fue su autor material o simplemente dictó unas ideas que fueron materializadas finalmente por los escribanos de la corte (probablemente más lo segundo que lo primero), aquí el dato importante es la forma autobiográfica que adquirió finalmente el Llibre dels Fets, la crónica del rey.

El texto histórico deviene, sobre todo a partir del siglo XII, un instrumento privilegiado para la consolidación de la cultura aristocrática y monárquica, aunque ambas utilizan procedimientos historiográficos muy diferentes. Junto a la vernacularización del texto histórico, se produce una elocuente prosificación. La emergencia de la prosa en sustitución del verso, de la lengua vernacular en lugar del latín, de la historia en lugar de la ficción, incrementa la credibilidad de la ideología aristocrática y monárquica. La prosa da una sensación de realismo mayor que el verso, que había sido utilizado hasta entonces para las narraciones épicas y de ficción. La lengua vernácula, cada vez más extendida, otorga a la narración histórica una flexibilidad mucho mayor que el latín. Apropiándose de la inherente autoridad de los textos latinos y adaptando la prosa para la historización del lenguaje literario, la historiografía vernacular emerge como una literatura del hecho, integrando a un nivel literario la experiencia histórica y construyendo un lenguaje expresivo y narrativo, propio de la aristocracia ${ }^{61}$.

60 SPIEGEL, Gabrielle M.: «Social Change and Literary Language: The Textualization of the Past in Thirteenth-Century French Historiography», en Journal of Medieval and Renaissance Studies 17 (1987), pp. 129-148.

61 «By appropiating the inherent authority of latin texts and by adapting prose for historization of literary language, vernacular historiography emerges as literature of fact, integrating on a literary level the historical experience and the expressive language proper to the aristocracy» (SPIEGEL, Gabrielle M.: The Past as Text, p. 193). 


\section{CONCLUSIONES: DEL HISTORICISMO AL POSTMODERNISMO}

La aproximación tradicional a los textos de la historiografía medieval, desde una perspectiva racionalista y positivista, no es hoy día suficiente. Quizás nos hemos dejado llevar demasiado tiempo por una idea de progreso excesivamente materializada y determinista. Hemos aplicado nuestra idea mecanicista del progreso al análisis de los textos de otros períodos, cuando el contexto intelectual en el que fueron articulados es totalmente diferente al nuestro. Es evidente que deben preservarse los métodos más tradicionales del medievalismo, pero no es menos cierto que quizás deba prestarse más atención a las nuevas corrientes, relacionadas de un modo u otro con el postmodernismo, que permiten un acceso a los textos históricos más poliédrico e interdisciplinar.

Hace unos años, la medievalista norteamericana Kathleen Biddick, en una imagen quizás excesivamente retórica, apuntaba que el presentismo lleva a los medievalistas a mirar en el espejo de la edad media para reflejar en él historias que, en realidad, pertenecen a los tiempos modernos y hasta postmodernos ${ }^{62}$. El presentismo domina sobre el preterismo, su opuesto, en nuestra relación con la época medieval, porque somos capaces de identificar la edad media más como un espejo que como un espejismo. Este es, desde luego, un efecto muy saludable del presentismo, que nos ayuda a identificarnos con el tiempo analizado, por muy lejano que sea, y a comprenderlo mejor. Pero, indudablemente, el presentismo tiene también el posible efecto perverso de analizar esa época lejana aplicándole anacrónicamente los parámetros de la cultura actual. En todo caso, es preciso no dejarnos arrastrar excesivamente por nuestra mentalidad racionalista, que nos lleva a reducir la interpretación de la historiografía medieval al grado de verosimilitud de las crónicas medievales. El análisis de las crónicas medievales ha permanecido demasiado tiempo sujeto a los parámetros de la investigación científica, muy segura de sí misma pero quizás excesivamente unívoca. Esto ha llevado a algunos especialistas a rechazar buena parte de lo que tiene de aprovechable la historiografía como fuente documental y como artefacto retórico.

A primera vista, el abandono de las certidumbres positivistas y del racionalismo de la New History de los Annales y del materialismo histórico aparece como un paso atrás para la historiografía actual. Sin embargo, en el campo concreto del análisis de la historiografía medieval, un sano relativismo ha permitido a los historiadores recelar de los planteamientos excesivamente herméticos de los paradigmas de la posguerra (materialismo histórico, estructuralismo braudeliano, cuantitativismo cliométrico) y caer más en la cuenta de la función mediatizadora del lenguage y, por tanto, generar un fructífero diálogo disciplinar con filólogos, críticos literarios y lingüistas. Como comenta Gabrielle Spiegel, el principal efecto del giro lingüístico para los historiadores ha sido alertarles de la fuerza mediado-

62 BIDDICK, Kathleen: The Shock of Medievalism, Durham \& London, 1998, p. 83. 
ra del lenguaje en la representación del pasado, y ayudarles a entender que no hay un accceso directo a los hechos históricos ni a las personas, por lo que todo texto histórico, sea medieval o moderno, realiza siempre una aproximación al pasado a través de los discursos, sean estos del tipo que sean. ${ }^{63}$ El sentido común del historiador le lleva a no absolutizar excesivamente el influjo del lenguaje, dotándole de una inverosímil realidad ontológica, contraria al sentido común; pero, al mismo tiempo, le ayuda a caer en la cuenta de la importancia de su función mediadora, salvando su referencialidad con el mundo real.

Los historiadores dedicados al análisis de la historiografía medieval deben superar la fase de la desmitificación de los textos históricos, de la distinción de lo verdadero y lo falso. Los estructuralismos, marxismos y cuantitativismos (paradigmas historiográficos de posguerra ${ }^{64}$ no fueron capaces de valorar en su justa medida la historiografía medieval, porque denunciaban su bajo nivel literario, su narrativa ininteligible y poco coherente, su equívoca noción de la evidencia histórica, su falta de sentido cronológico, sus intenciones propagandísticas y manipuladoras, su tendencia al simbolismo y su querencia por la ficción, los mitos y los milagros en detrimento de las certidumbres históricas. Como consecuencia, el análisis de los textos históricos medievales perdió interés, o se restringió a consideraciones de tipo formal, en una época donde el predominio de lo socioeconómico era apabullante. En este sentido, la bistoria des mentalités, practicada por los historiadores de la tercera generación de los Annales como Georges Duby y Jacques Le Goff durante los años 70 y 80, representó una transición-todavía no un precidente- entre los viejos paradigmas y las tendencias asociadas al giro lingüístico, no tanto por los postulados teóricos que defendían como por el cambio de orientación en sus temas de interés.

El postmodernismo tiene evidentemente muchas lagunas y todavía muchas preguntas por responder. Sin embargo, ha tenido tantos efectos positivos en la lectura de las crónicas porque ha sabido apreciar su naturaleza eminentemente narrativa. Sintomáticamente, la reaparición del lenguaje narrativo en la historiografía a partir de los años setenta ${ }^{65}$, en detrimento de los cerrados discursos de los grandes paradigmas cuantitativistas y economicistas de la posguerra, ha tenido como consecuencia una revalorización de aquellas fuentes históricas basadas en la narración más que en la esquematización: de este modo, los histo-

63 "The principal effect of the linguistic turn, for historians, has been to alert us to the mediating force of language in the representation of the past, and thus to help us to understand that there is no direct access to historical events or persons, so that all historical writing, whether medieval or modern, approaches the past via discourses of one sort or another» (SPIEGEL, Gabrielle M.: The Past as Text, pp. XVI-XVII).

64 STONE, Lawrence: "The revival of narrative: reflections on a new old history», en The Past and the Present, Boston, 1981, pp. 75-79.

65 Los primeros exponentes de esta nueva corriente en el campo del medievalismo fueron los libros de DuBY, Georges: Le Dimanche de Bouvines, 27 juillet 1214, París, 1973 y Le RoY LADURIE, Emmanuel: Montaillou, Village occitan de 1294 à 1324, París, 1975. 
riadores hemos redescubierto el valor literario e histórico de las crónicas, y los críticos literarios han sabido apreciar también su dimensión contextual. Todo esto está relacionado también con que la historiografía actual pone más énfasis en el consumo que en la producción ${ }^{66}$, en el capital simbólico más que en el capital material ${ }^{67} \mathrm{y}$, en definitiva, en el código lingüístico más que en el contenido mismo de lo transmitido. Los historiadores han encontrado en los códigos lingüísticos unos inmejorables síntomas del desarrollo de una cultura específica ${ }^{68}$.

Por su simplicidad y expresividad, la historiografía medieval merece un tratamiento específico por parte del historiógrafo contemporáneo. En primer lugar, el historiador debe despojarse de los prejuicios de la crítica moderna, que ha establecido unas reglas del juego bien diferentes a las que presidían el trabajo de los cronistas medievales. Los textos históricos medievales deben ser leídos en sí mismos como unos fenómenos culturales, devolviéndolos al contexto social desde donde fueron creados y desde donde recibieron una forma y un contenido precisos. De este modo, el historiador y el crítico literario contemporáneo pueden percibir cómo la historiografía medieval fue penetrada y modificada por el cambio social; y, al contrario, en qué medida esa misma historiografía, en un interesante proceso «de ida y vuelta», fue capaz de modificar el propio contexto social y político en la que se hallaba inserta -función pasiva y activa de la historiografía.

La fuerza y la legitimación de la función de la historiografía medieval está asegurada por el mismo talante de la sociedad de aquel periodo, en la que, como explicaba el medievalista norteamericano Joseph Strayer, cada deliberada modificación de una actividad preexistente en el pasado debía estar basada en el estudio de los precedentes; cada plan para el futuro dependía en buena medida de lo que había sucedido en el pasado ${ }^{69}$. Por este motivo, nuestros parámetros de verosimilitud histórica no son válidos para acercarse a la realidad historiográfica de la edad media, porque, para los cronistas medievales, el recuerdo del pasado no es sólo la memoria de los hechos históricos sino, todavía más importante, la promesa del futuro: «Praeteritorum recordatio futurorum est exhibitio».

La historiografía medieval se convierte así en una excelente fuente para investigar la función del pasado en las sociedades tradicionales. Las sociedades, una vez que han madurado, construyen su vida de acuerdo con su visión de la historia. Esto es especialmente aplicable a la época medieval, donde predomi-

66 CHAlINE, Jean-Pierre: «Qu'est-ce qu'un bourgeois?», L'Histoire, 121 (abril, 1989), pp. 38-45.

67 Bourdieu, Pierre: La Distinction. Critique sociale du jugement, París, 1979.

68 Sobre la nueva historia cultural, ver los volúmenes recopilatorios, HuNT, Lynn, ed.: The New Cultural History, Berkeley, 1989 y Bonell, Victoria E. Y HunT, Lynn, eds.: Beyond the Cultural Turn. New Directions in the Study of Society and Culture, Berkeley, Cal., 1999.

69 «Every deliberate modification of an existing type of activity must be based on a study of individual precedents. Every plan for the future is dependent on a pattern which has been found in the past» (STRAYER, Joseph R., en BARZUN, Jacques, et alt., eds.: The Interpretation of History, Princeton, 1943, p. 10). 
naba la autoridad de los precedentes históricos, la tradición y las costumbres ${ }^{70}$. Un estudio adecuado de las crónicas medievales debería permitirnos acceder no sólo a un mejor conocimiento de las sociedades medievales desde las que fueron articuladas, sino también a la mejor comprensión de los mecanismos y las motivaciones que han regulado la escritura de la historia a lo largo de todas las épocas, desde la clásica a la postmoderna. Atendiendo al enorme interés que han despertado en otros ambientes académicos internacionales, las tendencias analizadas en este artículo deberían gozar de una mayor atención en el ámbito del medievalismo español. No se pide obviamente un posicionamiento radical ante ellas, en sentido positivo o negativo, pero sí el abandono de ciertas posturas de rechazo acrítico o escéptico, que únicamente contribuyen a ocultar artificiosamente un debate historiográfico que dura ya tres décadas, y del que el medievalismo español no puede desentenderse tan fácilmente.

70 Bloch, Marc: Feudal Society, Chicago, 1964, I, p. 114. 